\title{
Focal-Mechanism Determination in Taiwan by Genetic Algorithm
}

\author{
by Yih-Min Wu, Li Zhao, Chien-Hsin Chang, and Ya-Ju Hsu
}

\author{
Online Material: Focal mechanisms for January 1991-December $2005 M_{\mathrm{L}} \geq 4.0$ \\ Taiwan earthquakes.
}

\begin{abstract}
We determined the focal-mechanism solutions for earthquakes with magnitude $M_{\mathrm{L}} \geq 4.0$ that occurred in the Taiwan region between 1991 and 2005. Firstmotion polarities of $P$ waves recorded at over 700 seismic stations in Taiwan were used. Because of the large number of events and stations involved, we implemented the genetic algorithm in a nonlinear global search for the focal-mechanism solutions. The algorithm was tuned and validated through synthetic tests. We finally determined the focal mechanisms of 1635 events with good qualities among 4188 earthquakes. Focal-mechanism solutions for a majority of the earthquakes display a dominant pattern of thrust-fault type reflecting the compressive stress field due to the plate collision. Normal-fault events occurred at intermediate depths in subduction zones, which is likely the result of the bending of the subducting slabs. Strike-slip faults are also found within the Eurasia plate around the Peikang Basement High and in collision zones near Ilan where the geometry of the colliding plates is complex. Our study provides a database of focal mechanisms for studying seismogenic structures and plate tectonics. This database can also be used by structural seismologists to compute synthetics for waveform tomography studies.
\end{abstract}

\section{Introduction}

Taiwan is situated in one of the most tectonically and seismically active regions in the world. It is the place where two plates, the Eurasian and the Philippine Sea plates, collide with each other. Along the Ryukyu trench in the east, the Philippine Sea plate plunges northward under the Eurasian plate. To the south of the island of Taiwan in the South China Sea, the Eurasian plate subducts eastward under the Philippine Sea plate. Figure 1 is a schematic diagram showing the major geologic settings in the region. The Longitudinal Valley (LV) in southeast Taiwan is the suture zone between the Eurasian and the Philippine Sea plates. This suture zone separates Taiwan into two major tectonic provinces. The eastern side consists of the Coastal Range and several volcanic islands and is the leading edge of the Philippine Sea plate. The western province is part of the Eurasian continental shelf (Ho, 1999) and can be classified into four northnortheast-south-southwest-trending geological belts. They are, from west to east, the Coastal Plain, the Western Foothills, the Hsueshan Range, and the Central Range.

As a result of the regional tectonic activities, most parts of Taiwan have been under a northwest-southeast compression with a convergence rate of about $8 \mathrm{~cm} / \mathrm{yr}$ (Yu et al., 1997). The Taiwan orogeny, started around 4 Ma (Suppe, 1984), is relatively young on the geological time scale. The high rate of crustal deformation leads to strong seismic activity, with hundreds of earthquakes of magnitude 4 and above every year. These abundant, moderate-sized earthquakes provide a good natural laboratory to study both the earth structure and the earthquake sources. Determining the focal mechanisms of these moderate-sized earthquakes is not only a seismologically challenging task, but it can also provide information on the state of regional tectonic stress and the seismotectonic environment. A systematic focalmechanism catalog can also be used in other applications such as waveform tomography.

The polarities of $P$-wave first motions can be used to determine the focal mechanisms of a large number of earthquakes efficiently. It is, however, a nonlinear optimization process. Commonly used methods are the iterative gradient search (Udias and Buforn, 1988) and grid search algorithms (Snoke et al., 1984; Reasenberg and Oppenheimer, 1985; Snoke, 2003), although both have their difficulties. The problem with the iterative gradient search is the existence of local minima, while the grid search option can avoid the problem of local minima but is computationally expensive for high-resolution studies. Thus, an efficient and economic global search algorithm is necessary.

The genetic algorithm (GA) is one of the powerful, established tools for nonlinear optimization problems. Proposed in Holland (1975), it has become a fully developed 


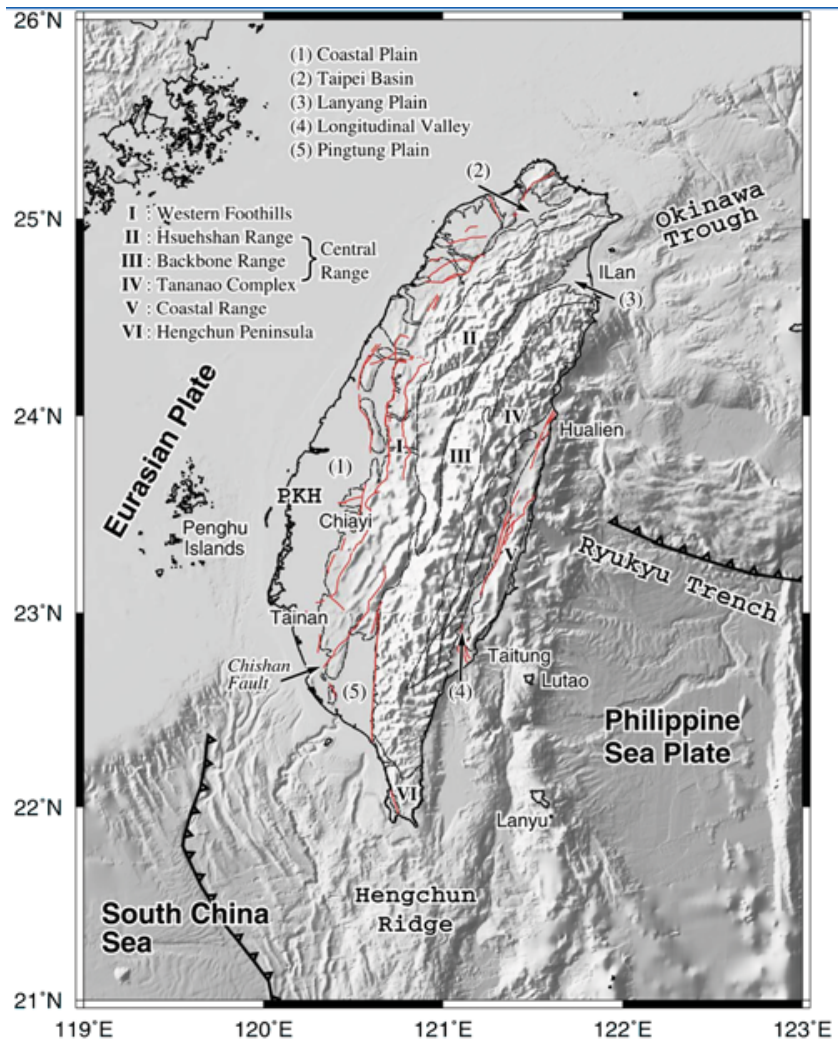

Figure 1. Map of the Taiwan region showing the topography and geological settings. Red lines show locations of active faults.

approach to nonlinear optimization (e.g., Goldberg, 1989; Davis, 1991; Sen and Stoffa, 1995) and has been applied to a variety of scientific problems. It has also been widely used in seismology on waveform inversions (e.g., Sambridge and Drijkoningen, 1992), earthquake locations (e.g., Sambridge and Gallagher, 1993; Billings et al., 1994), crustal structure investigations (e.g., Zhou et al., 1995a; Yamanaka and Ishida, 1996; Bhattacharyya et al., 1999; Chang et al., 2004; Lawrence and Wiens, 2004; Pezeshk and Zarrabi, 2005), and focal mechanism and other source parameter estimations (e.g., Kobayashi and Nakanishi, 1994; Yin and Cornet, 1994; Zhou et al., 1995b; Sileny, 1998; Koper et al., 1999; Jimenez et al., 2005).

The genetic algorithm was first used in determining the focal mechanisms from the first-motion polarities of $P$ waves by Kobayashi and Nakanishi (1994), and since then, many researchers have investigated the retrieval of the focal mechanism as a deviatoric moment tensor based on the GA method (e.g., Yin and Cornet, 1994; Zhou et al., 1995b; Sileny, 1998; Koper et al., 1999). Here, we adopt the same technique to systematically determine the focal mechanisms of moderatesized earthquakes in Taiwan, where $\sim 18,000$ events have been recorded digitally every year since 1994 in a region of about $400 \times 550 \mathrm{~km}$ by the Taiwan Central Weather Bureau Seismic Network (CWBSN). This huge dataset provides a great challenge and an excellent opportunity for us to use the GA method to determine the focal mechanisms for seismotectonic studies.

As a global search algorithm, the genetic algorithm is not a fail-safe method in finding the global minimum. Some careful considerations are necessary in determining the parameters involved in the GA method. In the next two sections, we briefly describe the procedures in our implementation of the GA method and the synthetic tests for configuring the genetic algorithm for the purpose of focal-mechanism determination. Then we present the solutions obtained by our GA method to the first-motion focal mechanisms for $M_{\mathrm{L}} \geq 4$ earthquakes in the Taiwan region and discuss their regional seismotectonic implications.

\section{The Genetic Algorithm}

Goldberg (1989) provides a comprehensive description of the genetic algorithm, which is adopted in our study. The algorithm involves three operators of the natural selection, namely the reproduction, crossover, and mutation. The algorithm can be summarized as follows:

1. Generate the first generation.

2. Decode: In achieving the focal-mechanism resolution up to $1^{\circ}, 25$ bits are used to represent the fault-plane parameters: strike $\left(0^{\circ}\right.$ to $\left.360^{\circ}\right)$, dip $\left(0^{\circ}\right.$ to $\left.90^{\circ}\right)$, and rake $\left(-180^{\circ}\right.$ to $\left.180^{\circ}\right)$, which occupies 9 bits, 7 bits, and 9 bits, respectively. The best resolution is up to about $0.7^{\circ}$.

3. Evolution: We keep a few percent of parents with the best fitness for reproduction. The fitness (fit) is defined by the agreement of the first-motion polarities. Its range is from 0 for no agreement to 1 for a complete match. Three-point crossover is used in this study for considering three fault-plane parameters. The parents are randomly selected from among the 50\% good fitness in the last generation. The mutation causes some bit reversal from 1 to 0 or 0 to 1 during the crossover process. We repeat this procedure until the maximum generation is reached. The population and maximum generation, and the percentage of reproduction, crossover, and mutation are determined from synthetic tests.

4. Output the result with the best fitness, and estimate its uncertainty and solution quality. First we identify solution clusters, check the solutions by considering the main planes and auxiliary planes, and remove redundant solutions. We determine the mean of each cluster and treat it as the result and then calculate the 2 S.D. as the uncertainty. Well-constrained data have only one solution cluster with a small uncertainty. Poorly constrained data generally produce a large uncertainty. We also define a quality index, $Q_{f p}$, for the final solution

$$
Q_{f p}=Q_{\text {gap }} \cdot Q_{\text {fitness }} \cdot Q_{\text {readings }} \cdot Q_{\text {polarity }},
$$

where $Q_{\text {gap }}=(180-$ gap $) / 90$ for gap $\leq 180$, and $Q_{\text {gap }}=0$ for gap $>180 ; \quad Q_{\text {fitness }}=($ fit -0.7$) / 0.15$ 
for fit $\geq 0.7$, and $Q_{\text {fitness }}=0$ for fit $<0.7 ; Q_{\text {readings }}=$ $(N r-10) / 20$ for $10 \leq N r \leq 50, \quad Q_{\text {readings }}=0$ for $N r<10$, and $Q_{\text {readings }}=2$ for $N r>50$; and $Q_{\text {polarity }}=$ $\left(0.5-\left|N_{u p} / N r-0.5\right|\right) / 0.25$. Here, gap is the largest azimuthal separation in degrees between two adjacent first-motion polarities projected on the Lambert-Schmidt equal-area projection circle, $\mathrm{Nr}$ is the total number of polarity readings, and $N_{u p}$ is the number of compressional polarity readings. Generally, $Q_{f p}=0$ is a no-constraint solution, and $Q_{f p}>1$ is considered a good solution. Figure 2 gives four examples of focal mechanisms with different qualities.

The aforementioned procedure forms the optimization part of the algorithm for determining focal mechanisms. We used the 3D pseudobending ray-tracing algorithm (Thurber, 1993; Thurber and Eberhart-Phillips, 1999) in predicting the polarization of the $P$-wave first motions.

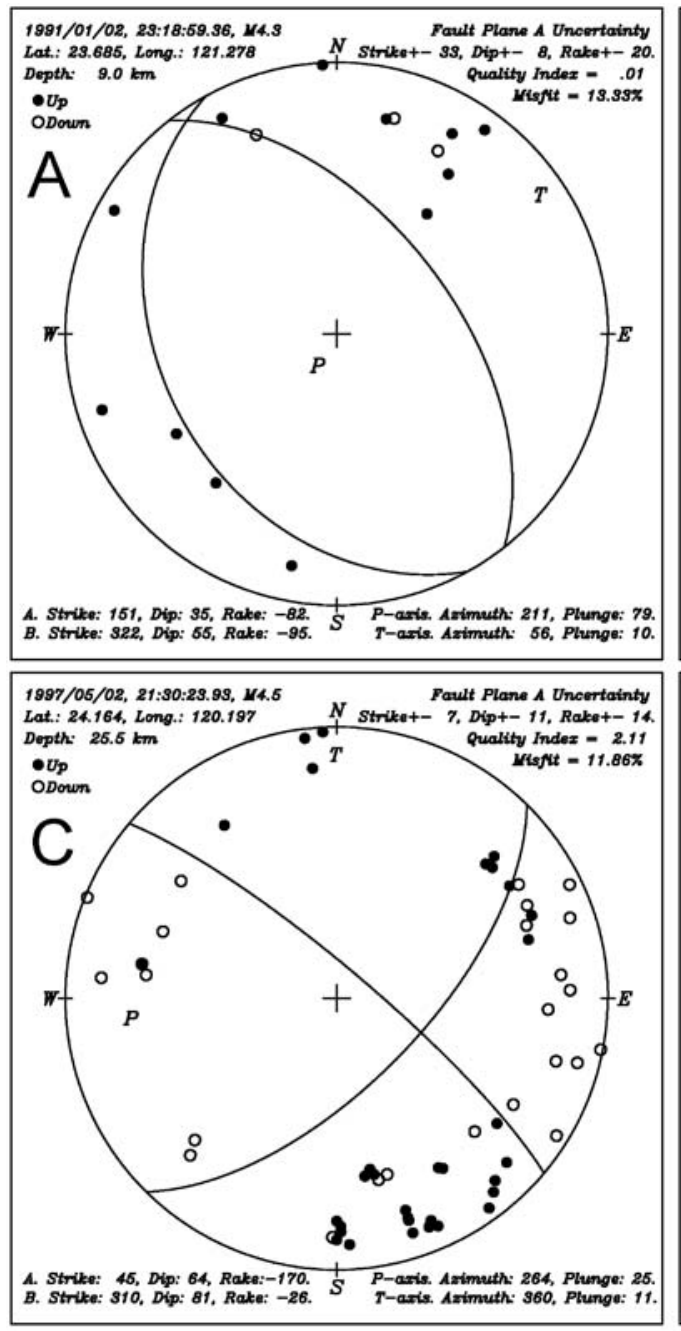

\section{Synthetic Tests}

The GA is not a fail-safe method in finding the global minimum. The parameters have to be tuned according to particular problems at hand. For this purpose, we conducted a test of 1000 synthetic events to find the optimal parameters that provide reliable focal-mechanism solutions. Each synthetic event contains 100 polarities randomly produced from a fault-plane solution under the condition that the coverage gap is less than $180^{\circ}$ and that the percentage of upward (compressional) first-motion polarities is between $10 \%$ and $90 \%$. We calculated the average number of search times required for finding the exact solutions for the 1000 synthetic events using various combinations of the parameters involved. We started with different populations under the fixed condition of $5 \%$ reproduction rate, $55 \%$ crossover, $40 \%$ mutation, and 3-bit reversal for each mutation. The test results are shown in Figure 3. We found that the population of 800 had the mini-

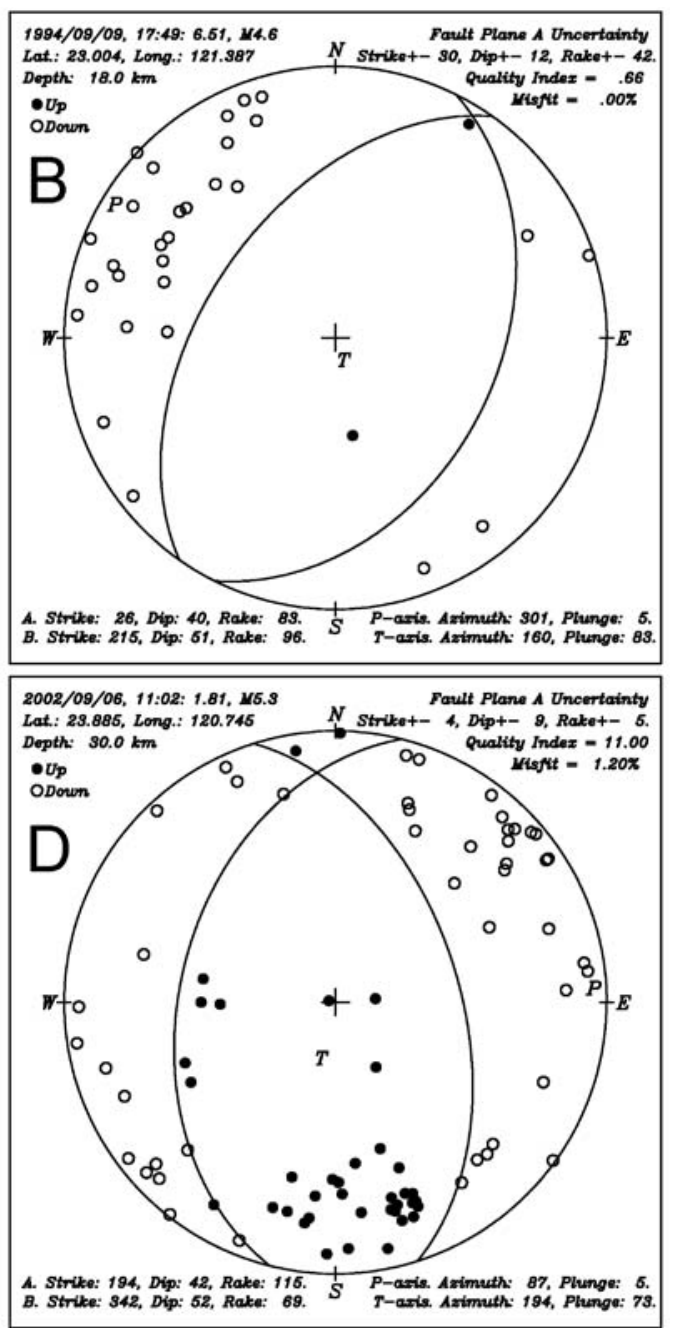

Figure 2. Four focal-mechanism solutions with different quality indices. (a) A solution with a very low quality index value due to a large GAP, poor polarity fitness, and a small number of the dilatational first-motion readings; (b) a solution of a low-quality index value due to a small number of compressional first-motion readings; (c) a relatively poor polarity fitness results in a low-quality index value; (d) an example with a very good constraint. 
mum average number of search times. Then we used the fixed population of 800 to find the optimal reproduction rate of $3.6 \%$. Next, we found that reversing 3 bits for each mutation and a mutation rate of $72 \%$ are the best parameters for mutation. Finally, we determined the pure crossover rate to be $24.4 \%$. Under these parameters, an average of 3746 searches were needed to find the best solution. Based on this testing result, we set the value of maximum generation to 20 with about 16,800 search times for practical operation. This number is sufficient to find the best solution, and it takes only a few seconds of computation time for each event.

We also carried out a comparison of the fitness and the central processing unit (CPU) times between our GA approach and the FPFIT program by Reasenberg and Oppen- heimer (1985) using a $2^{\circ}$ grid for 1635 events in Taiwan (E) see Table 2 in the electronic edition of BSSA). On a Pentium®4 PC with $2.40 \mathrm{GHz}$ processor, our method took about $24 \mathrm{~min}$, with an average fitness of $0.97 \pm 0.04$. On the other hand, the FPFIT took 1632 min with the same average fitness of $0.97 \pm 0.04$. This comparison demonstrates conclusively the efficiency and effectiveness of our GA approach to the determination of first-motion focal mechanisms.

\section{Results: Focal Mechanisms of Taiwan Earthquakes}

In this study, we used the first-motion polarities from the CWBSN and the Taiwan Strong Motion Instrumentation Program (TSMIP). The CWBSN consists of 71 real-time velocityrecording stations, whereas $\sim 680$ free-field strong-motion

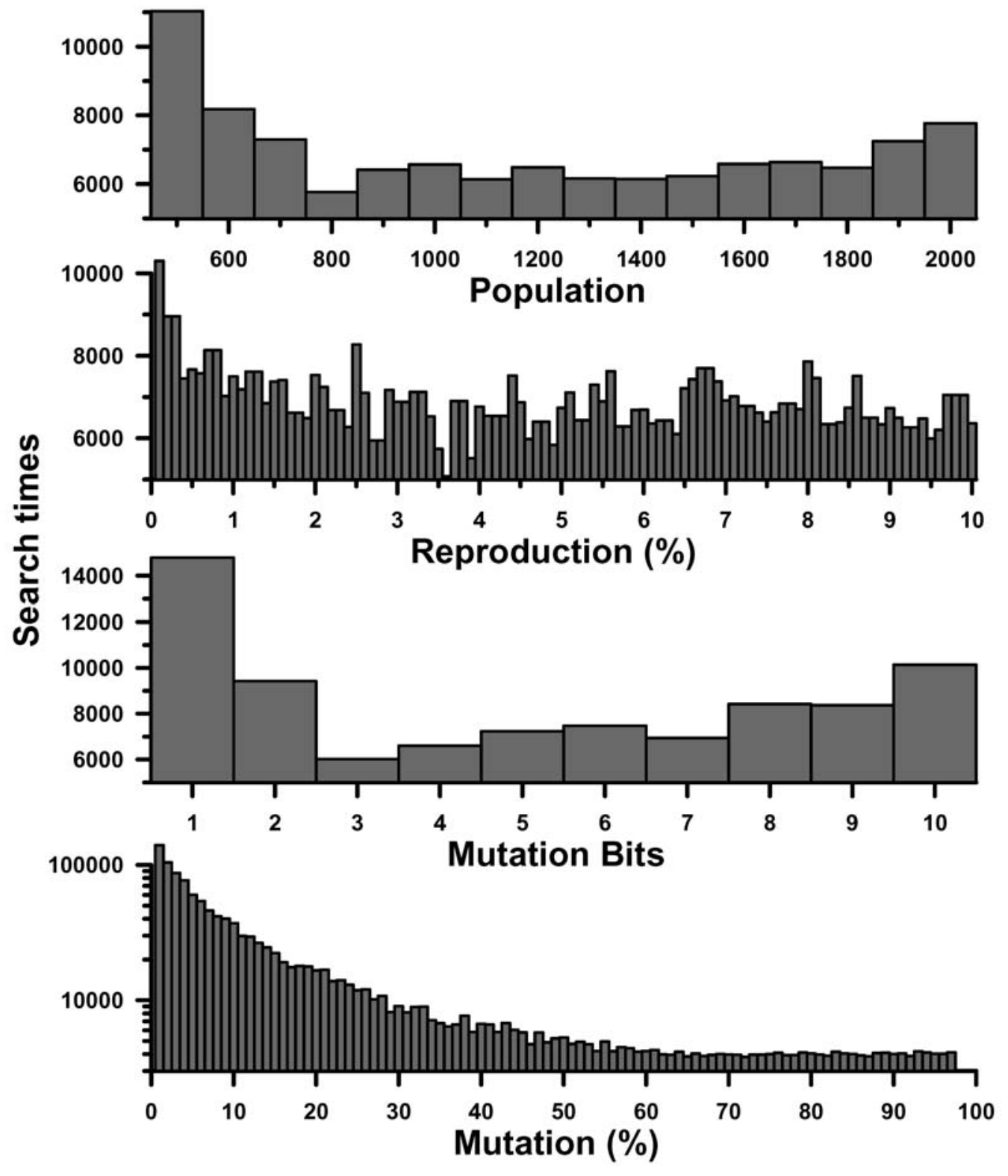

Figure 3. Average numbers of searches versus different settings of the GA parameters in the synthetic test. 
stations form the TSMIP network. Figure 4 depicts the station distributions of two networks.

Before applying the genetic algorithm to determine the focal mechanisms, we first relocated all the events using a new regional 3D model and the $P$ - and $S$-wave arrival times from CWBSN stations and the $S$ - $P$ times from TSMIP stations. Details of the regional 3D model can be found in Wu et al. (2007). Relocation of all events between 1991 and 2005 using the 3D model will be presented in a separate publication (Wu et al., 2008).

Our target in this study is to determine the focal mechanisms of earthquakes with $M 4$ and above. Between 1991 and 2005, there were a total of 4188 such events, among which 2090 have $P$-wave first-motion polarity readings less than 10 or gap $>180^{\circ}$. We further rejected events with $Q_{\text {gap }} \cdot Q_{\text {readings }} \cdot Q_{\text {polarity }}<0.1$, which resulted in a total of 1824 events for which we used the GA method to determine the focal mechanisms. In general, most of events are inland or near offshore. Offshore events with large gap generally cannot be well determined. The solutions for 32 events with $M_{\mathrm{L}} \geq 6.0$ are listed in Table 1. Figure 5 shows the average uncertainty of the strike, dip, and rake versus $Q_{f p}$ of the 1824 events. The overall trend is that a better quality has a smaller average uncertainty, and vice versa. Most of uncertainties are less than $30^{\circ}$, and the mean of average uncertainty is $18^{\circ}$ with a standard deviation of $13^{\circ}$. In addition, we provide the list of

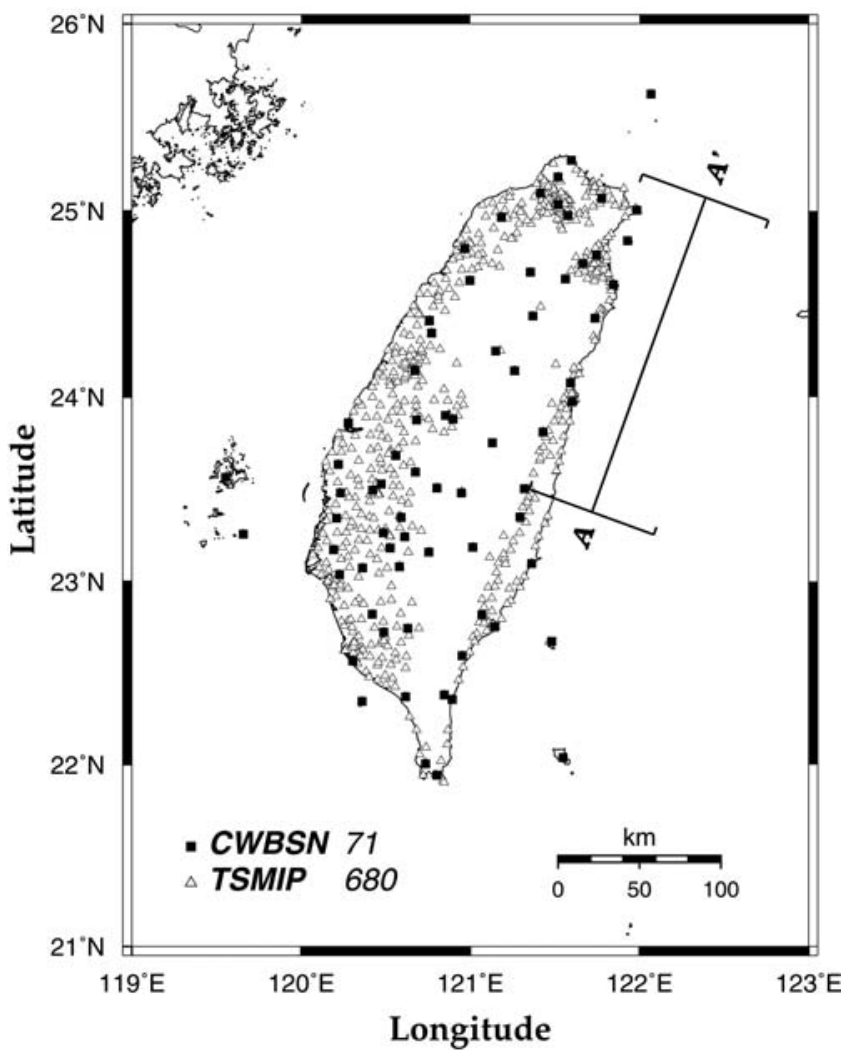

Figure 4. Station distributions of the CWBSN and TSMIP. $A A^{\prime}$ shows the location of the profile in Figure 10. the 1635 events with average uncertainties less than $45^{\circ}$ in $(E)$ Table 2 in the electronic edition of BSSA.

Focal mechanisms of the shallow events were plotted in Figure 6. It can be seen that most of the earthquakes in Taiwan are dominated by thrust faulting. Here, to facilitate the understanding of the characteristics of regional tectonics, we discuss these focal mechanisms in the context of the four different seismogenic zones (Wu and Chen, 2007).

1. Western Seismic Zone: The region is located in the Eurasian plate. Most of the earthquakes occurred in this zone can be associated with active faults in the western foothills. There have been large disastrous earthquakes in this region such as the 1999 Chi-Chi earthquake occurred in central Taiwan (Wang, 1998; Chang et al., 2000; Yu et al., 2001; Hsu, 2003; Chang et al., 2007). Many earthquakes in this region are related to the Chi-Chi aftershock sequence. The distribution of seismicity in this region can be related to the Peikang Basement High (e.g., Mouthereau et al., 2002), a high velocity barrier in western Taiwan as indicated in Figure 7 that shows the Vp perturbation at depths between 17 and $21 \mathrm{~km}$, the seismicity with $M_{\mathrm{L}} \geq 3.0$, and focal depths less than $30 \mathrm{~km}$ (Wu et al. 2007). To examine regions with earthquake clusters, we plot the trend of compressive axes as well as the faulting types based on the focal-mechanism results and the stress analysis. The analysis of the regional stress field was conducted using the algorithm developed by Michael $(1984,1987)$ based on minimizing the misfit of each fault-plane solution's both nodal planes to the best-stress tensor to determine the orientation of the principal stresses. The study area was divided into a grid of $0.25^{\circ} \times 0.25^{\circ}$, and we used at least 10 earthquakes within a box of about $50 \times 50 \mathrm{~km}$ to estimate the principal stress axes. In order to define the meaningful confidence region in the stress tensor inversion, we used a bootstrap method by resampling the data 200 times to generate 200 new datasets to conduct the stress tensor inversions. The surface-projected $\sigma_{1}$ and $\sigma_{3}$ axes within the $68 \%$ confidence region are plotted in Figure 8 . We find that the thrust events are dominant, but there are strike-slip faulting as well, consistent with a northwestsoutheast trending compression. A few normal-type focal mechanisms can be found close to west coast region, and many shallow earthquakes with normal-faulting mechanisms occurred in the central range (on the eastern boundary of this zone). We suggest that it is an indication of compressional pop-up structures (Kuochen et al., 2004), considering the ongoing mountain building in Taiwan and that the region is bounded by thrust faults. The western central range is bounded by a well-known thrust faults system, including the Chelungpu fault. The eastern boundary of the central range is the LV. Surface geology and geomorphology (Biq, 1965; Shyu et al., 2006) suggest the existence of a west-dipping thrust-fault bounding the western margin of the LV. A modeling test on the 
Table 1

Source Parameters of the $32 M_{\mathrm{L}} \geq 6.0$ Earthquakes Determined in This Study

\begin{tabular}{|c|c|c|c|c|c|c|c|c|c|}
\hline Origin Time (UTC) (mm/dd/yyyy hh/mm/ss) & Longitude $\left({ }^{\circ} \mathrm{E}\right)$ & Latitude $\left({ }^{\circ} \mathrm{N}\right)$ & Depth $(\mathrm{km})$ & $M_{\mathrm{L}}$ & Strike $\left({ }^{\circ}\right)$ & Dip $\left(^{\circ}\right)$ & Rake $\left({ }^{\circ}\right)$ & $Q_{f p}$ & $N r^{*}$ \\
\hline 06/05/1994 01:09:30 & 121.838 & 24.460 & 10.8 & 6.5 & $13 \pm 22$ & $44 \pm 18$ & $-132 \pm 44$ & 6.31 & 101 \\
\hline 06/25/1995 06:59:05 & 121.673 & 24.552 & 50.0 & 6.5 & $40 \pm 3$ & $58 \pm 6$ & $153 \pm 4$ & 4.13 & 61 \\
\hline 03/05/1996 14:52:28 & 122.242 & 24.009 & 9.1 & 6.4 & $92 \pm 5$ & $64 \pm 2$ & $106 \pm 8$ & .45 & 33 \\
\hline 07/29/1996 20:20:54 & 122.257 & 24.512 & 66.8 & 6.1 & $57 \pm 5$ & $63 \pm 5$ & $150 \pm 29$ & 3.50 & 136 \\
\hline 10/11/1997 18:24:25 & 122.535 & 25.007 & 147.0 & 6.1 & $26 \pm 10$ & $67 \pm 7$ & $-35 \pm 52$ & .48 & 39 \\
\hline 07/17/1998 04:51:14 & 120.656 & 23.507 & 4.7 & 6.2 & $37 \pm 12$ & $39 \pm 2$ & $109 \pm 11$ & 5.79 & 80 \\
\hline 06/03/1999 16:11:44 & 122.351 & 24.425 & 64.7 & 6.2 & $59 \pm 1$ & $39 \pm 1$ & $114 \pm 1$ & 5.63 & 57 \\
\hline 09/20/1999 17:47:15 & 120.805 & 23.853 & 7.0 & 7.3 & $208 \pm 5$ & $59 \pm 5$ & $115 \pm 19$ & 6.01 & 88 \\
\hline 09/20/1999 17:57:15 & 121.013 & 23.938 & 12.8 & 6.4 & $140 \pm 12$ & $67+3$ & $88 \pm 5$ & 1.35 & 22 \\
\hline 09/20/1999 18:03:41 & 120.884 & 23.802 & 9.4 & 6.6 & $16 \pm 16$ & $76 \pm 8$ & $-102 \pm 13$ & .78 & 68 \\
\hline 09/20/1999 21:46:36 & 120.852 & 23.664 & 1.2 & 6.6 & $1 \pm 32$ & $39 \pm 19$ & $77 \pm 31$ & 3.39 & 40 \\
\hline 09/22/1999 00:14:40 & 121.025 & 23.848 & 4.9 & 6.8 & $16 \pm 21$ & $46 \pm 12$ & $125 \pm 29$ & .57 & 45 \\
\hline 09/22/1999 00:49:43 & 121.042 & 23.750 & 24.4 & 6.2 & $197 \pm 13$ & $69 \pm 14$ & $103 \pm 14$ & .28 & 30 \\
\hline 09/22/1999 12:17:20 & 120.999 & 23.742 & 25.4 & 6.0 & $173 \pm 1$ & $32 \pm 1$ & $125 \pm 1$ & .50 & 31 \\
\hline 09/25/1999 23:52:49 & 120.981 & 23.847 & 11.5 & 6.8 & $179 \pm 10$ & $66 \pm 6$ & $96 \pm 6$ & 2.17 & 75 \\
\hline 10/22/1999 02:18:56 & 120.428 & 23.488 & 20.8 & 6.4 & $39 \pm 5$ & $51 \pm 7$ & $125 \pm 9$ & 10.29 & 47 \\
\hline 10/22/1999 03:10:17 & 120.450 & 23.525 & 16.9 & 6.0 & $237 \pm 2$ & $72 \pm 3$ & $154 \pm 5$ & 6.24 & 92 \\
\hline 11/01/1999 17:53:02 & 121.652 & 23.387 & 42.6 & 6.9 & $4 \pm 1$ & $47 \pm 1$ & $56 \pm 1$ & 7.07 & 75 \\
\hline 06/10/2000 18:23:29 & 121.091 & 23.892 & 21.1 & 6.7 & $5 \pm 19$ & $46 \pm 6$ & $78 \pm 18$ & 3.14 & 74 \\
\hline 07/28/2000 20:28:07 & 120.919 & 23.408 & 5.1 & 6.1 & $85 \pm 6$ & $72 \pm 28$ & $-177 \pm 25$ & 6.39 & 38 \\
\hline 09/10/2000 08:54:46 & 121.559 & 24.057 & 20.4 & 6.2 & $72 \pm 12$ & $70 \pm 6$ & $172 \pm 6$ & 2.77 & 65 \\
\hline 06/13/2001 13:17:56 & 122.392 & 24.416 & 71.8 & 6.3 & $54 \pm 3$ & $53 \pm 4$ & $146 \pm 35$ & 3.84 & 47 \\
\hline 06/14/2001 02:35:25 & 121.927 & 24.428 & 22.8 & 6.3 & $93 \pm 6$ & $58 \pm 6$ & $6 \pm 21$ & 10.72 & 45 \\
\hline 02/12/2002 03:27:25 & 121.652 & 23.765 & 40.5 & 6.2 & $18 \pm 6$ & $46 \pm 2$ & $57 \pm 12$ & 6.46 & 88 \\
\hline 03/31/2002 06:52:50 & 122.163 & 24.167 & 16.5 & 6.8 & $66 \pm 15$ & $80 \pm 1$ & $91 \pm 8$ & 1.04 & 35 \\
\hline 05/15/2002 03:46:06 & 121.857 & 24.655 & 12.2 & 6.2 & $49 \pm 3$ & $34 \pm 1$ & $-94 \pm 5$ & 1.27 & 57 \\
\hline 08/28/2002 17:05:34 & 121.385 & 22.263 & 20.5 & 6.0 & $224 \pm 23$ & $79 \pm 15$ & $118 \pm 11$ & .56 & 44 \\
\hline 06/10/2003 08:40:32 & 121.630 & 23.521 & 44.1 & 6.5 & $217 \pm 1$ & $57 \pm 1$ & $115 \pm 1$ & 4.70 & 85 \\
\hline 12/10/2003 04:38:13 & 121.382 & 23.078 & 21.9 & 6.4 & $8 \pm 6$ & $50 \pm 3$ & $74 \pm 8$ & 3.73 & 47 \\
\hline 05/19/2004 07:04:12 & 121.369 & 22.712 & 21.2 & 6.0 & $75 \pm 1$ & $13 \pm 1$ & $97 \pm 1$ & 3.80 & 86 \\
\hline 11/11/2004 02:16:43 & 122.214 & 24.309 & 21.9 & 6.1 & $89 \pm 7$ & $61 \pm 9$ & $98 \pm 7$ & 1.41 & 79 \\
\hline 06/01/2005 16:20:05 & 122.060 & 24.639 & 65.2 & 6.0 & $43 \pm 3$ & $24 \pm 1$ & $145 \pm 13$ & 2.72 & 68 \\
\hline
\end{tabular}

" $\mathrm{Nr}$ is the number of polarity readings.

Global Positioning System (GPS) data (Johnson et al., 2005) and a study on the seismogenic fault of the 2006 Taitung earthquake (Wu, Chen, Chang, et al., 2006) also support this suggestion.

The trend of the maximum horizontal stress in a collision zone such as the Taiwan orogeny generally corresponds to the maximum compressive stress axis, $\sigma_{1}$. From the earthquake focal mechanisms with depth less

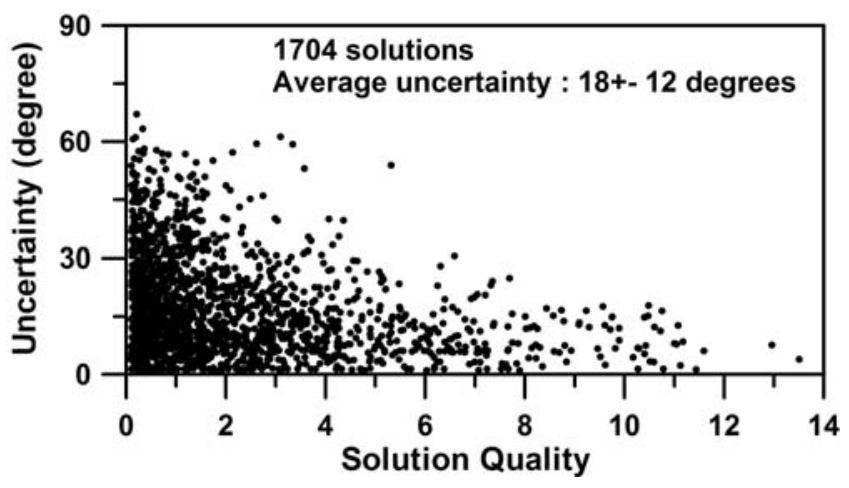

Figure 5. Uncertainties of the 1824 focal-mechanism solutions versus quality index. than $30 \mathrm{~km}$, we estimated that the plunge of $\sigma_{1}$ is close to horizontal, and the trend of $\sigma_{1}$ has a fan-shaped pattern (Fig. 8) in this region. The result is in agreement with earlier studies based on the focal mechanisms of 200 earthquakes (Yeh et al., 1991), borehole breakouts (e.g., Suppe et al., 1985), fault-slip data (e.g., Angelier et al., 1986), and the principal shortening direction derived from the GPS velocity field (Bos et al., 2003; Chang et al., 2003). However, there are certain areas near the northern $\left(\sim 121.3^{\circ} \mathrm{E}, 24.3^{\circ} \mathrm{N}\right)$ and southern $\left(121^{\circ} \mathrm{E}\right.$, $23^{\circ} \mathrm{N}$ ) tips of the central range, where $\sigma_{1}$ axes are close to vertical, indicating normal faulting with northeastsouthwest extension (Fig. 8). In addition, the intermediate stress axis, $\sigma_{2}$, seems to vary significantly from north to south in western Taiwan. The $\sigma_{2}$ axes are close to vertical near the northern and southern ends of the 1999 ChiChi coseismic rupture, corresponding to the observed strike-slip faults on the surface (Lee et al., 2002) and the seismogenic structures revealed by previous studies (Kao and Chen, 2000; Kao and Angelier, 2001). Areas near the Chi-Chi epicenter show mainly thrust faulting with vertical $\sigma_{3}$ axes. In the Chiayi and Tainan regions, either $\sigma_{2}$ or $\sigma_{3}$ is close to vertical, suggesting the exis- 

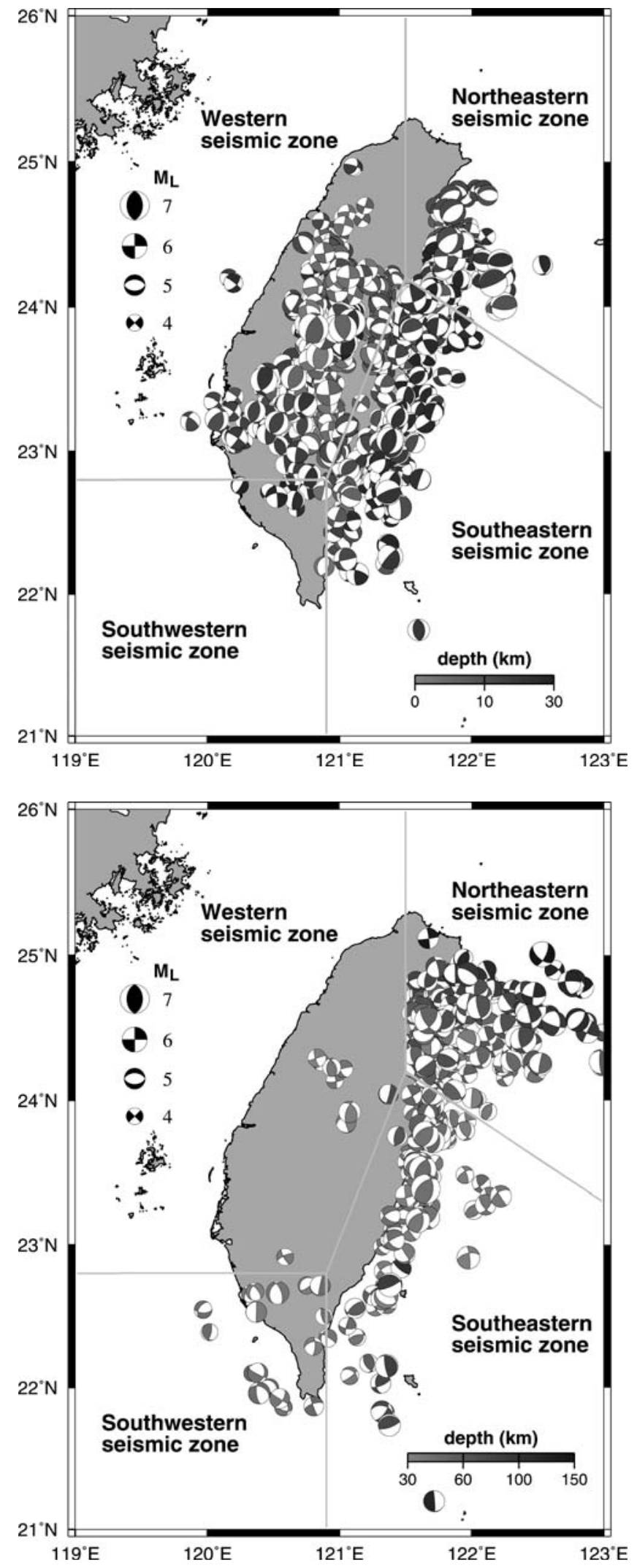

Figure 6. (a) Focal mechanisms determined in this study for earthquakes with source depths less than $30 \mathrm{~km}$. (b) Focal mechanisms determined in this study for earthquakes with source depth large than $30 \mathrm{~km}$. Black lines indicate the boundaries of the four seismic zones discussed in the text.

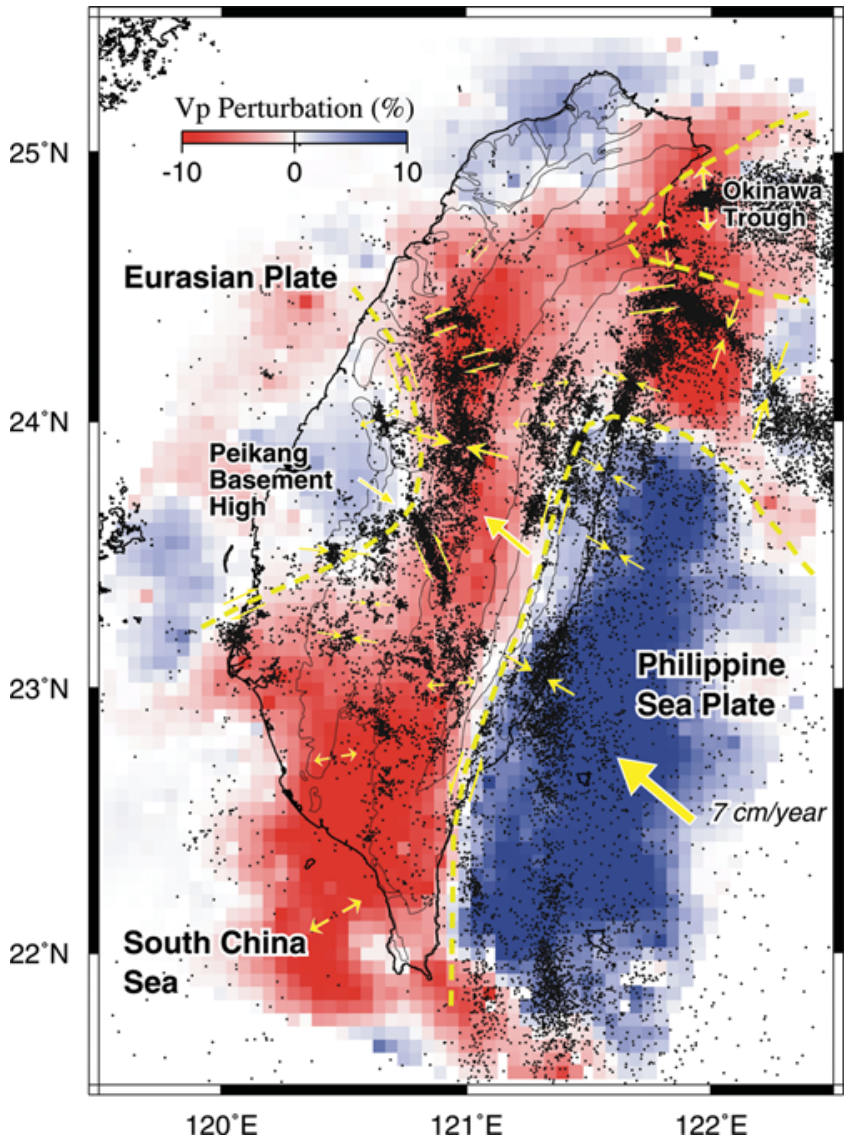

Figure 7. A composite map showing the Vp perturbation (color) at the depths between 17 and $21 \mathrm{~km}$, the epicenters (dots) of $M_{\mathrm{L}} \geq 3.0$ earthquakes with focal depth less than $30 \mathrm{~km}$, and simplified stress description (small yellow arrows) from focal mechanisms determined in this study.

tence of both strike slip and thrust faulting, consistent with geological data (Shyu et al., 2005).

2. Southwestern Seismic Zone: This zone is located mainly in the South China Sea block of the Eurasian plate. In terms of seismic activity, this is the least active zone among the four. Most earthquakes in this region have focal depths greater than $30 \mathrm{~km}$ with normal-faulting focal mechanisms. In this zone, the South China Sea block of the Eurasian plate subducts under the Philippine Sea plate. The normal-faulting earthquakes in this zone are likely associated with the bending of the plunging slab. Occasional large earthquakes can also cause damage in this region. For example, the 26 December 2007 $M_{\mathrm{L}} 7.0$ earthquake caused 2 deaths, 42 injures, and 3 building collapses, and it ruptured the submarine communications cables (National Disaster Prevention and Protection Commission, R.O.C., 2007).

3. Northeastern Seismic Zone: This zone corresponds to the Ryukyu subduction system and shows high seismicity with occasional damaging earthquakes (Wang, 1998). The intermediate-depth earthquakes in this zone are associated with the Philippine Sea plate subducting under the Eurasia plate, whereas shallow events occur as a re- 

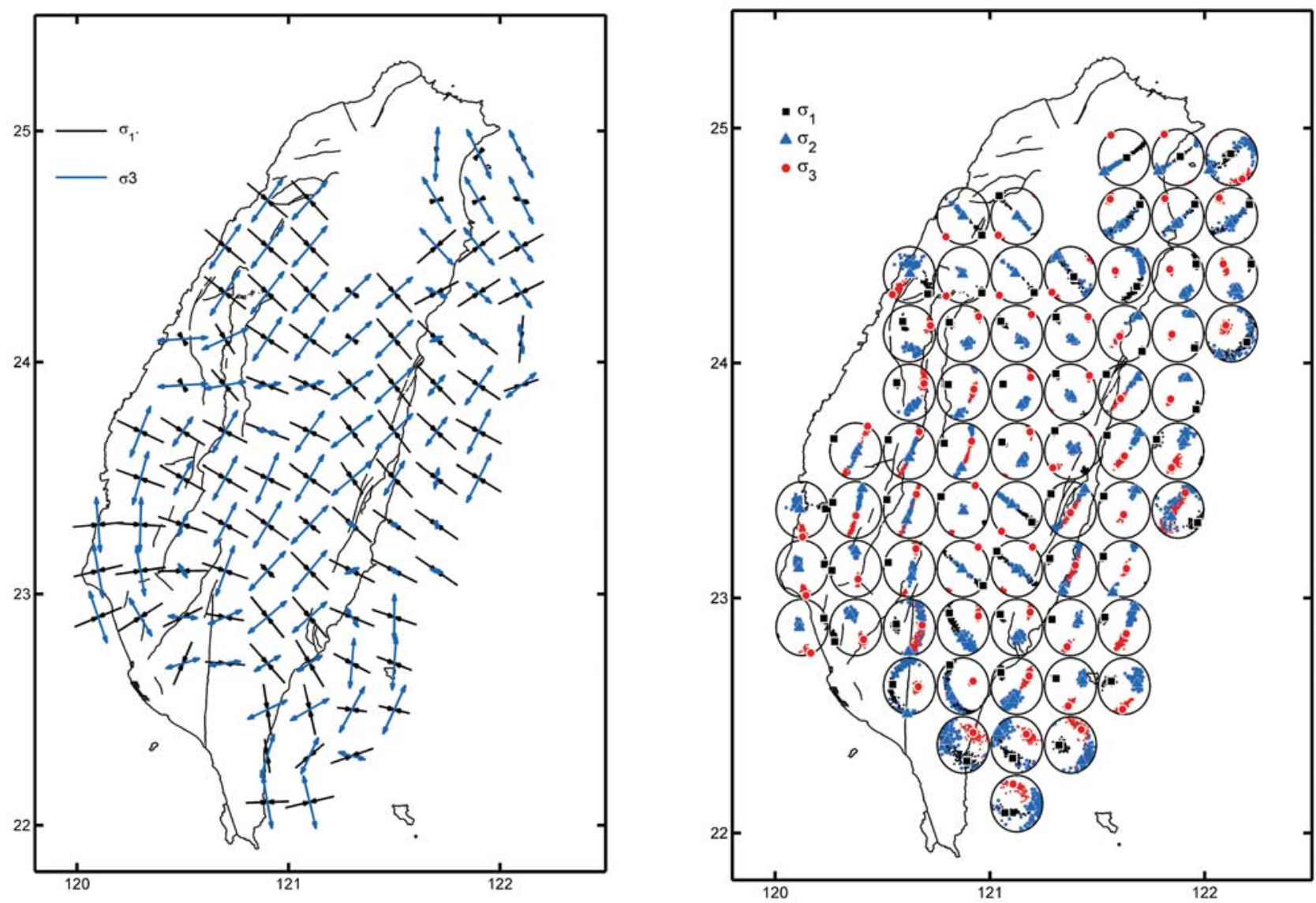

Figure 8. Result of the stress tensor inversion. (a) Surface projections of the $\sigma_{1}$ and $\sigma_{3}$ axes are plotted in black and blue arrows, respectively. (b) Different symbols represent different principal axes in equal-area projection of the lower hemisphere. The best solution is marked in large symbols. The small symbols show the distribution of stress axes within the $68 \%$ confidence region.

sult of the opening of the Okinawa trough and the collision between the Philippine Sea plate and the Eurasia plate. The trend of tensile axis is close to northwestsouthwest near Ilan plain (Fig. 8). Thus, focal mechanisms in this zone vary from thrust and strike-slip faulting in the south (Hualien), to normal faulting in the north (Ilan).

4. Southeastern Seismic Zone: This seismic zone is mainly caused by the collision of the Eurasia plate and the Luzon island arc on the Philippine Sea plate. As shown in Figure 7, a high $P$-wave velocity region is associated with the Philippine Sea plate. Because of the active collision between the continent and the island arc, most of the seismic activity in the Taiwan region, including many large earthquakes, occurs in this area (Wang, 1998) with primary thrust-type faulting (Kuochen et al., 2004; Wu, Chen, Shin, et al., 2006). However, because of the bending of the Philippine Sea plate (Kuochen et al., 2004), normal faulting is perceptible as well. In the Lanyu region, some deeper earthquakes are associated with the subduction of the South China Sea block of the Eurasian plate. The deformation inland is mostly confined in the
LV with the left-lateral oblique faulting such as the 2006 $M_{\mathrm{w}}$ 6.1 Taitung earthquake (Wu, Chen, Chang, et al., 2006). The stress tensor inversion shows that the orientation of either $\sigma 2$ or $\sigma 3$ is close to vertical in this region. In addition, we find the trends of $\sigma_{1}$ axes are rotated along the $\mathrm{LV}$ from $135^{\circ} \mathrm{N}$ in the northern $\mathrm{LV}$ to $115^{\circ} \mathrm{N}$ in the southern LV (Fig. 8). The counterclockwise rotation of the $\sigma_{1}$ axis along the LV from north to south may imply the spatial variation of fault slip in this region.

In southern Taiwan, we also find a clear counterclockwise rotation of the $\sigma_{1}$ axis, from $135^{\circ} \mathrm{N}$ near Taitung on the east coast to $80^{\circ} \mathrm{N}$ near Tainan on the west coast (Fig. 8). The change of stress orientation is likely related to the different state of stress in different geological provinces, that is, strong slate in the central range versus weak and thick mudstone in southwest Taiwan. An alternative explanation is that the variation of stress orientation could be related to different fault zones, such that the deformation is accommodated by the LV and the strike-slip faults (e.g., the Chishan fault) in southeast and southwest Taiwan, respectively. Moreover, studies from sand box experiments and structural evidence suggest that 
the tectonic escape of southwest Taiwan may be another explanation for the complexity of stress orientation ( $\mathrm{Lu}$ and Malavieille, 1994).

Many studies based on limited focal mechanisms have been conducted in the past in Taiwan tectonics (Kao, Jian, et al., 1998; Kao, Shen, and Ma, 1998; Kao and Rau, 1999; Chou et al., 2006). Focal mechanisms determined in this study provide an alternative database for the study of subduction systems. Figure 9 shows the seismicity and focal mechanisms in a northwest-southeast-trending profile in northeastern Taiwan. Several major features can be identified in this profile. At focal depths less than $50 \mathrm{~km}$, the predominant pattern is a thrust-type focal mechanism. However, as we mentioned in previous sections, strike-slip and normalfault mechanisms also occur due to the plate collision. At depths between 50 and $90 \mathrm{~km}$, there is a simple down-dip extensional regime, along the maximum tensile axis in the down-dip direction of the plunging slab (Kao and Chen, 1991; Kao, Shen, and Ma, 1998; Kao and Rau, 1999). At the depth of about $80 \mathrm{~km}$, the average dip of the slab changes slightly from $40^{\circ}-50^{\circ}$ to a steeper dip of about $60^{\circ}$. At depths larger than $120 \mathrm{~km}$, the focal mechanisms seem to shift to down-dip compression. However, due to the lack of firstmotion polarity data for intermediate-depth earthquakes, we were only able to determine only few focal mechanisms in this study.

Figure 10 shows the comparison of the focal mechanisms for large events determined by this study with those in the Harvard CMT Catalog, the USGS (Sipkin) momenttensor catalog, and determined through moment-tensor inversions by the Broadband Array in Taiwan for Seismology (BATS) (Kao, Jian, et al., 1998; Kao and Jian, 2001). Generally, there is a good agreement among the results by different studies. The discrepancies are expectable given that our solutions obtained from first-motion polarities reflect

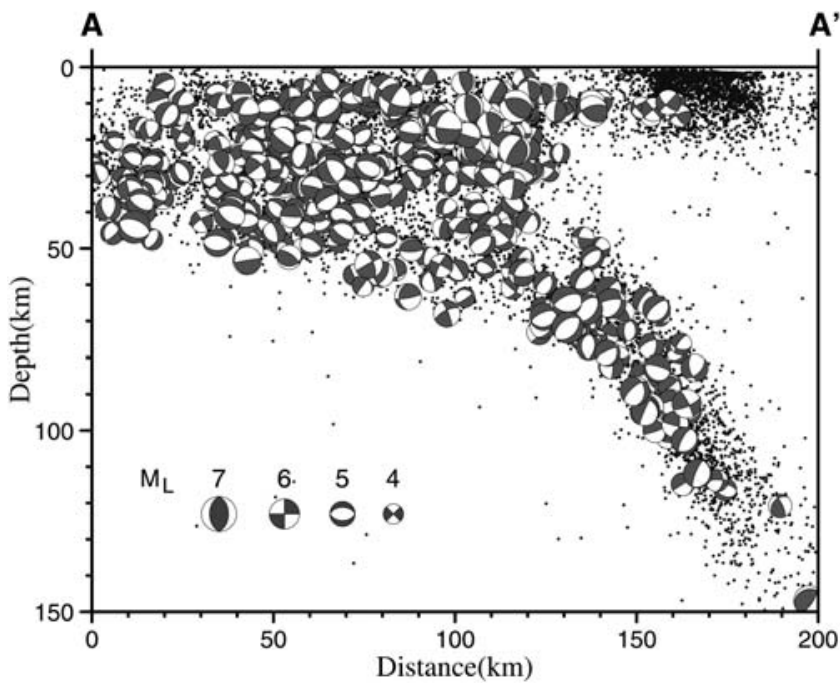

Figure 9. A profile of the focal-mechanism distribution in the subduction zone in northeastern Taiwan.
Harvard CMT BATS CMT USGS SIPKIN This study

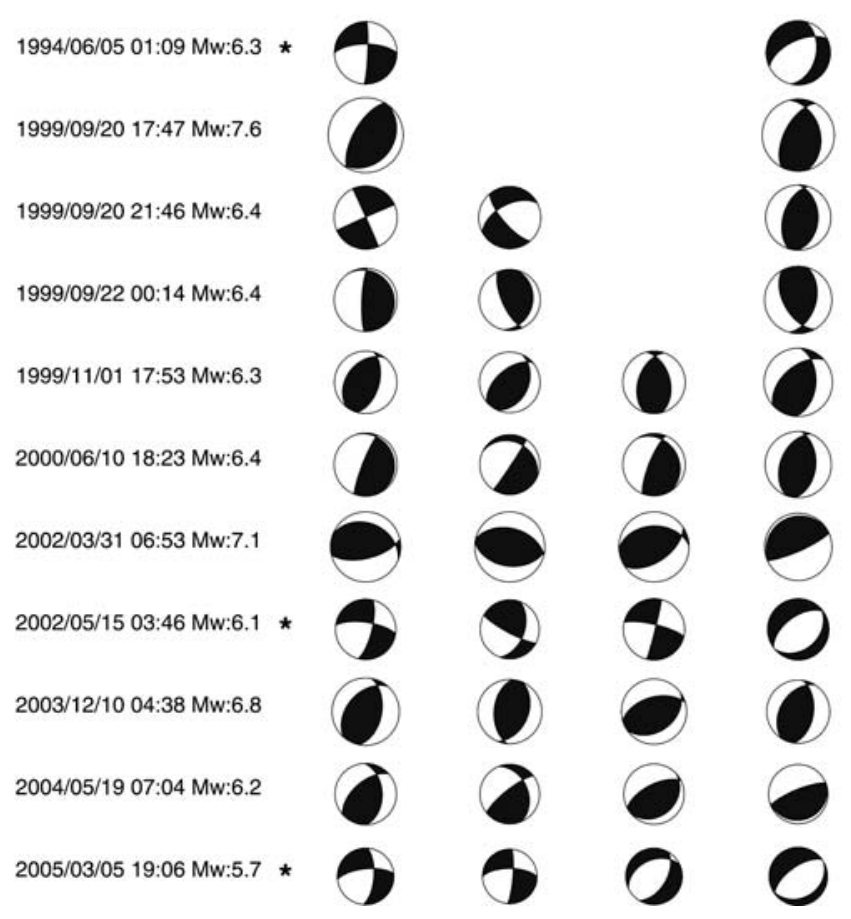

Figure 10. Comparison of focal mechanisms determined in this study and the Harvard, USGS (Sipkin), and BATS solutions.

the high-frequency behavior of the initial ruptures of the earthquakes, while Harvard and BATS solutions are obtained from long-period waveforms and are more representative of the average behavior of the entire sources. However, it is worth noting that for earthquakes near the Okinawa Tough (marked by stars in Fig. 10), solutions from first-motion polarities are close to normal faults, as opposed to strike-slip faulting in Harvard and BATS catalogs. The result of one event from the USGS (Sipkin) moment-tensor catalog is also a pure normal fault. This could be due to source ruptures of those three earthquakes, which may have larger highfrequency contents in their initiations. The USGS (Sipkin) moment-tensor solutions are obtained from relatively shortperiod $P$ waves. This may be the explanation of why our results are closer to the USGS (Sipkin) solutions. Further studies are needed for those earthquakes.

\section{Conclusion}

In this study, we have implemented the GA method. Synthetic tests were conducted to yield an efficient algorithm that provides reliable focal mechanisms. The algorithm also applies to the determination of first-motion focal mechanisms of earthquakes with magnitudes $M \geq 4$ in the Taiwan region.

First-motion polarities from the CWBSN and TSMIP were used to determine the focal mechanisms of about 1635 earthquakes. The overall feature shows the thrust-type focal mechanisms and reflects the compressive stress regime 
due to the plate collision. The trends of the $\sigma_{1}$ axis are in general consistent with the plate convergence direction of about $119^{\circ} \mathrm{N}$ (Seno et al., 1993) across the central half of the island of Taiwan. Normal-faulting events at intermediate depths off the coast of southern Taiwan are likely due to the bending of the subducting slab. Strike-slip faulting within the Eurasian plate and in collision zones is associated with the complex geometry of the colliding plates (Ilan). In addition, strike-slip faulting can be seen in the transfer zones such as northern and southern Chi-Chi ruptures as well as in southwest Taiwan. The focal mechanisms obtained here provide a database for the studies of seismogenic structures and plate tectonics. This database can also be used by structural seismologists to compute synthetics in waveform tomography studies.

Although in our implementation of the genetic algorithm we have used the polarities of first motions to determine the focal mechanisms, it can be easily adapted to using waveforms by changing the polarity fitness to the waveform fitness, which will be more useful in regions of poor station coverage. The computer program is written in Fortran 90 and is publicly available by request (contact Y.-M. Wu).

\section{Acknowledgments}

We thank Associate Editor Jeanne Hardebeck and the two reviewers Honn Kao and Arthur Snoke for their detailed comments, which greatly improved this article. This research was supported by the National Science Council (NSC95-2625-Z-002-028, NSC95-2119-M-002-043MY3, NSC95-2119-M-001-063, and NSC96-2116-M-001-011) with Taiwan Earthquake Research Center (TEC) Contribution Number 00017, the Central Weather Bureau of the Republic of China, and the Tectonics Observatory of the California Institute of Technology.

\section{References}

Angelier, J., E. Barrier, and H. T. Chu (1986). Plate collision and paleostress trajectories in a fold thrust belt: the foothills of Taiwan, Tectonophysics 125, 161-178.

Bhattacharyya, J., A. F. Sheeham, K. Tiampo, and J. Rundle (1999). Using a genetic algorithm to model broadband regional waveforms for crustal structure in the western United States, Bull. Seismol. Soc. Am. 89, 202214.

Billings, S. D., B. L. N. Kennet, and M. Sambridge (1994). Hypocentre location: genetic algorithms incorporating problem-specific information, Geophys. J. Int. 118, 693-706.

Biq, C. (1965). The east Taiwan rift, Petroleum Geol. Taiwan 4, 93-106.

Bos, A. G., W. Spakman, and M. C. J. Nyst (2003). Surface deformation and tectonic setting of Taiwan inferred from a GPS velocity field, J. Geophys. Res. 108, no. B10, 2458, doi 10.1029/2002JB002336.

Chang, S. J., C. E. Baag, and C. A. Langston (2004). Joint analysis of teleseismic receiver function and surface wave dispersion using the genetic algorithm, Bull. Seismol. Soc. Am. 94, 691-704.

Chang, C. P., T. Y. Chang, J. Angelier, H. Kao, J. C. Lee, and S. B. Yu (2003). Strain and stress field in Taiwan oblique convergent system: constraints from GPS observation and tectonic data, Earth Planet. Sci. Lett. 214, 115-127.

Chang, C. H., Y. M. Wu, T. C. Shin, and C. Y. Wang (2000). Relocating the 1999 Chi-Chi Earthquake, Taiwan, TAO 11, 581-590.
Chang, C. H., Y. W. Wu, L. Zhao, and F. T. Wu (2007). Aftershocks of the 1999 Chi-Chi, Taiwan, earthquake: the first hour, Bull. Seismol. Soc. Am. 97, 1245-1258, doi 10.1785/0120060184.

Chou, H., B. Kuo, S. Hung, L. Chiao, D. Zhao, and Y. Wu (2006). The Taiwan-Ryukyu subduction-collision complex: folding of a viscoelastic slab and the double seismic zone, J. Geophys. Res. 111, B04410, doi 10.1029/2005JB003822.

Davis, L. (Editor) (1991). Handbook of Genetic Algorithm, Van Nostrand Reinhold, New York.

Global Centroid Moment Tensor (CMT) Project catalog search, www. globalcmt.org/CMTsearch.html (last accessed May 2007).

Goldberg, D. E. (1989). Genetic Algorithms in Search, Optimization, and Machine Learning, Addison-Wesley, Reading, Massachusetts.

Ho, C. S. (1999). An Introduction to the Geology of Taiwan. Explanatory Text of the Geologic Map of Taiwan, Central Geological Survey/The Ministry of Economic Affairs, Taiwan.

Holland, J. H. (1975). Adaptation in the Natural and Artificial Systems, University of Michigan Press, Ann Arbor, Michigan.

Hsu, M. T. (2003). Seismological observation and service in Taiwan (up to 1970), in Handbook of Earthquake and Engineering Seismology, W. H. K. Lee, H. Kanamori and P. C. Jennings (Editors), Academic, New York.

Jimenez, A., J. M. Garcia, and M. D. Romacho (2005). Simultaneous inversion of the source parameters and attenuation factor using genetic algorithm, Bull. Seismol. Soc. Am. 95, 1401-1411, doi 10.1785/ 0120040116

Johnson, K. M., P. Segall, and S. B. Yu (2005). A viscoelastic earthquake cycle model for Taiwan, J. Geophys. Res. 110, B10404, doi 10.1029/ 2004JB003516.

Kao, H., and J. Angelier (2001). Stress tensor inversion for the Chi-Chi earthquake sequence and its implications on regional collision, Bull. Seismol. Soc. Am. 91, 1028-1040.

Kao, H., and W. P. Chen (1991). Earthquakes along the Ryukyu-Kyushu arc: Starin segmentation, lateral compression, and thermomechanical state of the plate interface, J. Geophys. Res. 96, 21,443-21,485.

Kao, H., and W. P. Chen (2000). The Chi-Chi earthquake sequence: active, out-of-sequence thrust faulting in Taiwan, Science 288, 2346-2349.

Kao, H., and P. R. Jian (2001). Seismogenic patterns in the Taiwan region: insights from source parameter inversion of BATS data, Tectonophysics 333, 179-198.

Kao, H., and R. J. Rau (1999). Detailed structures of the subducted Philippine Sea plate beneath northeast Taiwan: a new type of double seismic zone, J. Geophys. Res. 104, 1015-1033.

Kao, H., P. R. Jian, K. F. Ma, B. S. Huang, and C. C. Liu (1998). Moment tensor inversion for offshore earthquakes east of Taiwan and their implications to region collision, Geophys. Res. Lett. 25, 3619-3622.

Kao, H., S. J. Shen, and K. F. Ma (1998). Transition from oblique subduction to collision: earthquakes in the southernmost Ryukyu arc: Taiwan region, J. Geophys. Res. 103, 7211-7229.

Kobayashi, R., and I. Nakanishi (1994). Application of genetic algorithms to focal mechanism determination, Geophys. Res. Lett. 21, 729732.

Koper, K., M. E. Wysession, and D. A. Wiens (1999). Multimodel function optimization with a niching genetic algorithm: a seismological example, Bull. Seismol. Soc. Am. 89, 978-988.

Kuochen, H., Y. M. Wu, C. H. Chang, J. C. Hu, and W. S. Chen (2004). Relocation of the eastern Taiwan earthquakes and its tectonic implications, TAO 15, 647-666.

Lawrence, J. F., and D. A. Wiens (2004). Combined receiver-function and surface wave phase-velocity inversion using a niching genetic algorithm: application to Patagonia, Bull. Seismol. Soc. Am. 94, 977988, doi 10.1785/0120030172.

Lee, J. C., H. T. Chu, J. Angelier, Y. C. Chan, J. C. Hu, C. Y. Lu, and R. J. Rau (2002). Geometry and structure of northern surface ruptures of the $1999 \mathrm{Mw}=7.6$ Chi-Chi Taiwan earthquake: influence from inherited fold belt structures, J. Struct. Geol. 24, 173-192. 
Lu, C. Y., and J. Malavieille (1994). Oblique convergence, indentation and rotation tectonics in the Taiwan mountain belt: insights from experimental modeling, Earth Planet. Sci. Lett. 121, 477-494.

Michael, A. J. (1984). Determination of stress from slip data - faults and folds, J. Geophys. Res. 89, 1517-1526.

Michael, A. J. (1987). Use of focal mechanisms to determine stress: a control study, J. Geophys. Res. 92, 357-368.

Mouthereau, F., B. Deffontaines, O. Lacombe, and J. Angelier (2002). Variations along the strike of the Taiwan thrust belt: basement control on structural style, wedge geometry, and kinematics, Geol. Soc. Am. Spec. Pap. 358, 31-54.

National Disaster Prevention and Protection Commission, R.O.C. (2007). Statistics on the losses on natural disaster, http://www.ndppc.nat. gov.tw/ (last accessed May 2007).

Pezeshk, S., and M. Zarrabi (2005). A new inversion procedure for spectral analysis of surface waves using a genetic algorithm, Bull. Seismol. Soc. Am. 95, 1801-1808.

Reasenberg, P. A., and D. Oppenheimer (1985). FPFIT, FPPLOT, and FPPAGE: Fortran computer programs for calculating and displaying earthquake fault-plane solutions, U.S. Geol. Surv. Open-File Rept. 85-739, $25 \mathrm{pp}$.

Sambridge, M., and G. Drijkoningen (1992). Genetic algorithm in seismic waveform inversion, Geophys. J. Int. 109, 323-342.

Sambridge, M., and K. Gallagher (1993). Earthquake hypocenter location using genetic algorithm, Bull. Seismol. Soc. Am. 83, 1467-1491.

Sen, M. K., and P. L. Stoffa (1995). Global Optimization Methods in Geophysical Inversion, Elsevier, Amsterdam.

Seno, T., S. Stein, and A. E. Gripp (1993). A model for the motion of the Philippine seaplate consistent with Nuvel-1 and geological data, $J$. Geophys. Res. 98, 17,941-17,948.

Shyu, J. B. H., K. Sieh, Y. G. Chen, and L. H. Chung (2006). Geomorphic analysis of the central range fault, the second major active structure of the Longitudinal Valley suture, eastern Taiwan, Geol. Soc. Am. Bull. 118, 1447-1462, doi 10.1130/B25905.1.

Shyu, J. B. H., K. Sieh, Y. G. Chen, and C. S. Liu (2005). Neotectonic architecture of Taiwan and its implications for future large earthquakes, J. Geophys. Res. 110, B08402, doi 10.1029/2004JB003251.

Sileny, J. (1998). Earthquake source parameters and their confidence regions by a genetic algorithm with a "memory", Geophys. J. Int. 134, 228 242 .

Snoke, J. A. (2003). FOCMEC: FOCal MEChanism determinations, in International Handbook of Earthquake and Engineering Seismology, W. H. K. Lee, H. Kanamori, P. C. Jennings and C. Kisslinger (Editors), Academic Press, San Diego, Chap. 85.12.

Snoke, J. A., J. W. Munsey, A. C. Teague, and G. A. Bollinger (1984). A program for focal mechanism determination by combined use of polarity and SV-P amplitude ratio data, Earthq. Notes 55, 15.

Suppe, J. (1984). Kinematics of arc-continent collision, flipping of subduction, and back-arc spreading near Taiwan, Mem. Geol. Soc. China 6 , 21-33.

Suppe, J., C. T. Hu, and Y. J. Chen (1985). Present-day stress directions in western Taiwan inferred from borehole elongation, Petrol. Geol. Taiwan 21, 1-12.

Thurber, C. H. (1993). Local earthquake tomography: velocities and Vp/Vs: theory, in Seismic Tomography: Theory and Practice, H. M. Iyer and K. Hirahara (Editors), Chapman and Hall, London, 563-583.

Thurber, C., and D. Eberhart-Phillips (1999). Local earthquake tomography with flexible gridding, Comput. Geosci. 25, 809-818.

Udias, A., and E. Buforn (1988). Single and joint fault-plane solutions from first-motion datam, in Seismological Algorithms, D. J. Doornbos (Editor), Academic Press, New York, 443-453.
Wang, J. H. (1998). Studies of earthquake seismology in Taiwan during the 1897-1996 period, J. Geol. Soc. China 41, 291-336.

Wu, Y. M., and C. C. Chen (2007). Seismic reversal pattern for the 1999 Chi-Chi, Taiwan, $M_{\mathrm{w}} 7.6$ earthquake, Tectonophysics 429, 125-132.

Wu, Y. M., C. H. Chang, L. Zhao, J. B. Shyu, Y. G. Chen, K. Sieh, and J. Avouac (2007). Seismic tomography of Taiwan: improved constraints from a dense network of strong motion stations, J. Geophys. Res. 112, B08312, doi 10.1029/2007JB004983.

Wu, Y. M., C. H. Chang, L. Zhao, T. L. Teng, and M. Nakamura (2008). A comprehensive relocation of earthquakes in Taiwan from 1991 to 2005, Bull. Seismol. Soc. Am. 98 (in press).

Wu, Y. M., Y. G. Chen, C. H. Chang, L. H. Chung, T. L. Teng, F. T. Wu, and C. F. Wu (2006). Seismogenic structure in a tectonic suture zone: with new constraints from $2006 \mathrm{Mw} 6.1$ Taitung earthquake, Geophys. Res. Lett. 33, L22305.

Wu, Y. M., Y. G. Chen, T. C. Shin, H. Kuochen, C. S. Hou, J. C. Hu, C. H. Chang, C. F. Wu, and T. L. Teng (2006). Coseismic vs. interseismic ground deformations, faults rupture inversion and segmentation revealed by $2003 M_{\mathrm{w}} 6.8$ Chengkung earthquake in eastern Taiwan, Geophys. Res. Lett. 33, L02312.

Yamanaka, H., and H. Ishida (1996). Application of the genetic algorithms to an inversion of surface-wave dispersion data, Bull. Seismol. Soc. Am. 86, 436-444.

Yeh, Y. H., E. Barrier, C. H. Lin, and J. Angelier (1991). Stress tensor analysis in the Taiwan area from focal mechanisms of earthquakes, Tectonophysics 200, 267-280.

Yin, J. M., and F. H. Cornet (1994). Integrated stress determination by joint inversion of hydraulic tests and focal mechanisms, Geophys. Res. Lett. 21, 2645-2648.

Yu, S. B., H. Y. Chen, L. C. Kuo, S. E. Lallemand, and H. H. Tsien (1997). Velocity field of GPS stations in the Taiwan area, Tectonophysics, 274, 41-59.

Yu, S. B., L. C. Kuo, Y. R. Hsu, H. H. Su, C. C. Liu, C. S. Hou, J. F. Lee, T. C. Lai, C. C. Liu, and C. L. Liu (2001). Preseismic deformation and coseismic displacements associated with the 1999 Chi-Chi, Taiwan, earthquake, Bull. Seismol. Soc. Am. 91, 995-1012

Zhou, R., F. Tajima, and P. L. Stoffa (1995a).Application of genetic algorithm to constrain near-source velocity structure for 1989 Sichuan earthquake, Bull. Seismol. Soc. Am. 85, 590-605.

Zhou, R., F. Tajima, and P. L. Stoffa (1995b). Earthquake source parameter determination using genetic algorithms, Geophys. Res. Lett. 22, 517520 .

Department of Geosciences

National Taiwan University

Taipei 106, Taiwan

drymwu@ntu.edu.tw

(Y.-M.W.)

Institute of Earth Sciences

Academia Sinica

Nankang, Taipei 115, Taiwan

(L.Z., Y.-J.H.)

Central Weather Bureau

Taipei 100, Taiwan

(C.-H.C.)

Manuscript received 5 May 2007 